\title{
Faktor-faktor yang Mempengaruhi Financial Distress Pada Perusahaan Manufaktur
}

\author{
Rifka Damayanti *1, Sri Hermuningsih ${ }^{2}$, Ratih Kusumawardhani ${ }^{3}$ \\ 1,2,3 Universitas Sarjanawiyata Tamansiswa \\ Correspondence email: rifkada21@gmail.com
}

\begin{abstract}
This study aims to determine the factors that influence financial distress in manufacturing companies in the goods and consumption industry sector. This research uses five variables, namely liquidity, leverage, profitability, firm growth as the dependent variable, and financial distress as the independent variable. The population in this study are manufacturing companies in the goods and consumption industry sector that have been listed on the Indonesia Stock Exchange (IDX) for the 2015-2019 period, amounting to 52 companies. The data collection method uses purposive sampling by using financial reports on manufacturing companies in the consumer goods and industrial sector. listed on the IDX in the 2015-2019 period. The results show that liquidity, leverage, profitability, and firm growth simultaneously affect financial distress in manufacturing companies listed on the Indonesia Stock Exchange for the period 2015-2019, liquidity has a significant effect on financial distress, leverage has no significant effect on financial distress, profitability has a significant effect on financial distress and firm growth have no significant effect on financial distress.
\end{abstract}

Keywords : Financial Distress, Firm Growth, Leverage, Liquidity and Profitability

\section{Pendahuluan}

Pertumbuhan ekomoni modern yang terjadi di Indonesia selama ini mengalami peningkatan yang signifikan secara terus menerus. Pertumbuhan ini berdampak adanya desakan bagi perusahaan agar mampu mengembangkan trobosan dan mampu memperluas pasar persaingan agar tidak kalah saing.Perusahaan yang kalah dalam bersaing akan mengalami pailit atau kebangkrutan, sebelum terjadinya pailit ini perusahaan akan mengalami financial distress (kesulitan keuangan) (Fatmawati, 2019). Financial distress dideskripsikan sebagai fase pasang surut perihal yang terjadi sebelum terjadinya kebangkrutan atau likuidasi (Almilia, 2003). Financial distress bisa diperhatikan ketika perusahaan sedang mendapati kesulitan keuangan dalam menyelesaikan tanggungan-tanggungannya membayar hutang (Platt \& Platt, 2002). Berita financial distress ini bisa menjadi review atas kebangkrutan sehingga manajemen bisa menjalankan aktifitas dengan cepat agar menahan masalah sebelum terjadinya kebangkrutan (Fauzy, 2019)

Menurut Permana, Ahmar, dan Djaddang (2017) Tiap-tiap perusahaan dibangun dengan maksud dapat memberikan keuntungan sehingga dapat bertahan atau tumbuh dalam waktu yang lama dengan tidak menghadapi likuidasi. Kebenarannya, anggapan tersebut tidak sering terjadi dengan baik sesuai harapan.berulang kali perusahaan yang telah berfungsi dalam periode yang lama dapat terpaksa berakhir atau dilikuidasi karena menghadapi kepailitan dalam keuangannya yang dapat menyebabkan gulung tikar atau kebangkrutan (Adriana, 2012). Studi perihal fenomena-fenomena kebangkrutan perlu ditindak lanjuti, untuk menaksir akan insiden kebangkrutan dimasa yang akan datang. Upaya yang dilakukan yaitu dengan mengkaji rasio-rasio keuangan perusahaan melalui cara seperti dalam riset ini Peristiwa ini memandang tidak sedikit gejala-gejala kebangkrutan yang dialami perusahaan-perusahaan di Indonesia. (Adriana, 2012). Likuiditas dipakai untuk memperkirakan seberapa besar kapasitas perusahaan akan melaksanakan kewajiban lancar mereka memakai aset lancarnya. Besarnya likuiditas perusahaan menunjukkan gambaran yang baik untuk pihak internal ataupun eksternal perusahaan sebab perusahaan mampu melaksanakan kewajiban lancarnya selama jatuh tempo. Hasil Emningtyas (2017) menyatakan bahwa variael likuiditas memiliki pengaruh pada variabel financial distress secara signifikan dan serta arah yang negative (Pusvita Indria Mei Susilowati, 2019).

Leverage menafsir besarnya aset dari perusahaan yang dibiayai atau berasal dari utang. Jikalau sebuah perusahaan yang pembayarannya sebagian besar dari utang pihak ketiga, tentunya akan memberikan risiko kesulitan dalam pembayaran akibat dari aset yang memiliki nilai kecil dari utang perusahaan. Variabel leverage mempunyai pengaruh terhadap financial distress secara signifikan dan arah yang positif (Pusvita Indria Mei Susilowati1, 2019). Profitabilitas menghitung kompetensi perusahaan dalam memakai aset untuk mendapatkan laba. Semakin besar rasio ini maka perusahaan semakin baik dalam menghasilkan laba. Penelitian Sari (2015) menyatakan bahwa variabel profitabilitas memberikan pengaruh negative yang signifikan terhadap financial distress (Pusvita Indria Mei Susilowati, 2019). 


\section{Metode}

Data yang digunakan dalam penelitian ini merupakan data yang bersifat kuantitatif, yaitu berupa data dalam bentuk laporan keuangan dalam Financial Data dan Ratios perusahaan manufaktur sektor industry barang dan konsumsi periode tahun 2015-2019 yang terdaftar di Bursa Efek Indonesia (Pawitri \& Alteza, 2020). Objek penelitian yang akan diteliti dalam penelitian ini, yang menjadi dasar dari proses pemilihan sampel, pengumpulan, dan penafsiran data atau keterangan yang diperoleh berkaitan dengan penelitian, adalah faktor-faktor yang mempengaruhi kondisi financial distress perusahaan dan financial distress itu sendiri. Dimana financial distress sebagai variabel Y diwakilkan oleh perusahaan listed dan delisted di Bursa Efek Jakarta(Brahmana, 2007). Peneliti menggunakan perusahaan di bidang manufaktur sektor industry barang dan konsumsi yang list di BEI pada periode 2015 - 2019 sebagai populasi penelitian. Teknik pengambilan sampel dalam penelitian ini menggunakan teknik purposive sampling dengan menggunakan kriteria-kriteria sebagai berikut: (1) Perusahaan manufaktur yang masih ada di BEI selama periode 2015 - 2019; (2) Perusahaan Manufaktur yang ada di BEI yang memiliki laporan keuangan yang dipublikasi selama periode 2015 - 2019 berturut-turut; dan (3) Perusahaan dengan mata uang rupiah di laporan keuangannya. Kriteria ini digunakan karena diperlukan saat menghitung Market Value of Equity setiap perusahaan pada Fact Book tahunan yang diterbitkan BEI.(Murni, 2018)

Penelitian ini termasuk dalam kategori penelitian asosiatif. Penelitian ini menggunakan metode kuantitatif yang merupakan metode penelitian yang digunakan untuk meneliti data yang bersifat statistik agar dapat menguji suatu hipotesis. Tujuan dari penelitian ini yaitu melihat bagaimana pengaruh suatu variabel terhadap variabel lainnya. Analisis statistik deskriptif menurut Ghozali (2011) digunakan untuk memberikan gambaran atau deskripsi suatu data yang dilihat dari nilai rata-rata (mean), standar deviasi, varian, maksimum, minimum, sum, range, kurtosis, dan skewness. Analisis satistik deskriptif secara obyektif mengklasifikasi, menganalisis, dan menginterpretasikan data yang diteliti untuk mempermudah memahami variabel-variabel yang digunakan dalam penelitian (Nabawi \& Efendi, 2018).

\section{Hasil}

Tabel 1

Uji Kelayakan Model Regresi

\begin{tabular}{|c|c|r|c|}
\hline Step & Chi-square & Df & Sig \\
\hline 1 & 1.853 & 8 & 0.985 \\
\hline
\end{tabular}

Sumber: data olahan

Tabel 1, kelayakan model regresi dinilai dengan menggunakan Hosmer and Lemeshow Test. Hasil uji ni menunjukkan nilai Chi-Square sebesar 1,853 dengan signifikansi sebesar 0,985. Berdasarkan hasil tersebut, nilai signifikansi lebih dari 0,50 maka disimpulkan model tersebut mampu memprediksi nilai observasinya.

Tabel 2

Hasil Uji Regresi Logistik

\begin{tabular}{|l|l|r|r|}
\hline & & \multicolumn{1}{|c|}{ B } & \multicolumn{1}{c|}{ S.E. } \\
\hline Step & Likuiditas & 3.283 & 1.295 \\
\hline & Leverage & 0.465 & 0.613 \\
\hline & Profitabilitas & 11.608 & 4.419 \\
\hline & Growth Firm & 3.984 & 2.141 \\
\hline & Constant & -4.385 & 2.093 \\
\hline
\end{tabular}

Sumber: data olahan

Tabel 2 menunjukkan kolom B yang diinterpretasikan ke dalam model regresi logistic, baris kesatu sampai keempat menunjukkan variable independen dan baris terakhir menunjukkan variabel dependen maka dapat disimpulkan persamaan regresi logistik yang dapat disusun adalah sebagai berikut:

$\mathrm{FD}=-4.385+3.283 \mathrm{LK}+0.465 \mathrm{LV}+11,608 \mathrm{~PB}+3,984 \mathrm{GF}$

Tabel 3

Hasil Uji Parsial

\begin{tabular}{|l|l|r|r|r|r|r|r|}
\hline & & \multicolumn{1}{|c|}{ B } & \multicolumn{1}{c|}{ S.E. } & \multicolumn{1}{c|}{ Wald } & \multicolumn{1}{c|}{ df } & \multicolumn{1}{c|}{ Sig. } & \multicolumn{1}{c|}{$\operatorname{Exp(B)}$} \\
\hline Step1a & Likuiditas & 3.283 & 1.295 & 6.433 & 1 & 0.011 & 26.667 \\
\hline & Leverage & 0.465 & 0.613 & 0.574 & 1 & 0.449 & 1.591 \\
\hline & Profitabilitas & 11.608 & 4.419 & 6.900 & 1 & 0.009 & 109991.8 \\
\hline & Growth Firm & 3.984 & 2.141 & 3.464 & 1 & 0.063 & 53.754 \\
\hline & Constant & -4.385 & 2.093 & 4.391 & 1 & 0.063 & 0.012 \\
\hline
\end{tabular}

Sumber: data olahan 
Tabel 3 menunjukkan bahwa variable likuditas yang diukur dengan current ratio (CR) berpengaruh positif terhadap financial distress pada perusahaan manufaktur sektor industry barang dan konsumsi yang terdaftar di BEI tahun 2015-2019, ditunjukkan dengan nilai beta sebesar 3,283 dengan signifikansi 0,011. Hasil penelitian ini konsisten dan sesuai dengan penelitian Atika (2012) yang menunjukkan bahwa rasio likuiditas berpengaruh positif terhadap prediksi financial distress. Maulidina (2014) dengan hasil penelitiannya ialah rasio likuiditas berpengaruh terhadap prediksi kondisi financial distress. Merksusiwa (2015) mengatakan bahwa likuiditas berpengaruh terhadap financial distress. Hasil penelitian Rusaly (2016) juga mengatakan bahwa rasio likuiditas berpengaruh positif terhadap prediksi financial distress. Hasil penelitian Ghofur (2018) juga mengatakan bahwa rasio likuiditas berpengaruh positif terhadap prediksi financial distress.

Penelitian ini menunjukkan bahwa variable leverage yang diinterpretasikan dengan debt ratio (DR) tidak berpengaruh positif terhadap financial distress pada perusahaan manufaktur sektor industry barang dan konsumsi yang terdaftar di BEI tahun 2015-2019,ditunjukkan dengan nilai beta sebesar 0,465 dengan signifikansi 0,449. Dikarenakan nilai signifikansinya melebihi 0,05 , maka dapat disimpulkan leverage tidak memiliki pengaruhyang signifikan dalam meprediksi terjadinya financial distress pada perusahaan manufaktur sektor industry barang dan konsumsi yang terdaftar di BEI. Hasil penelitian ini konsisten dan sesuai dengan penelitian sebelumnya yang dilakukan oleh Atika (2012) ialah rasio leverage tidak berpengaruh positif terhadap prediksi kondisi financial distress. Hasil penelitian dari Simarmata (2018) juga mengatakan bahwa rasio leverage tidak berpengaruh positif terhadap prediksi kondisi financial distress. Variable profitabilitas yang diinterpretasikan dengan return on asset (ROA) berpengaruh positif terhadap financial distress pada perusahaan manufaktur sektor industry barang dan konsumsi yang terdaftar di BEI tahun 20152019,ditunjukkan dengan nilai beta sebesar 11,608 dengan signifikansi 0,009. Hasil penelitian ini sesuai dengan Rusaly (2016) menyatakan bahwa rasio profitabilitas berpengaruh positif terhadap prediksi financial distress. Hasil penelitian Ghofur (2018) juga menyatakan bahwa rasio profitabilitas berpengaruh positif terhadap prediksi financial distress. Variabel Growth Firm (GF) berpengaruh negatif terhadap prediksi financial distress pada perusahaan manufaktur sektor industry barang dan konsumsi yang terdaftar di BEI tahun 2015-2019, ditunjukkan dengan nilai beta sebesar 3,984 dengan signifikansi 0,063. Dikarenakan nilai signifikansinya melebihi 0,05, maka dapat ditarik kesimpulan growth firm tidak memiliki pengaruh yang signifikan dalam meprediksi terjadinya financial distress pada perusahaan manufaktur sektor industry barang dan konsumsi yang terdaftar di BEI. Hasil penelitian ini sejalan dengan penelitian sebelumnya yang dilakukan Luh dkk (2015) yang menyebutkan firm growth berpengaruh negatif pada financial distress.

\section{Simpulan}

Penelitian ini menghasilkan bukti empiris yang berkaitan dengan factor factor yang mempengaruhi financial distress pada perusahaan manufaktur sektor industry barang dan konsumsi yang terdaftar di BEI pada periode 20152019. Hasil dari penelitian tentang financial distres disini dapat ditarik kesimpulan bahwa likuiditas, dan profitabilitas berpengaruh pada financial distress. Sementara, leverage dan firm growth tidak memiliki pengaruh pada financial distress.

\section{Daftar Pustaka}

Adriana, A. N. (2012). Analisis Prediksi Kebangkrutan Menggunakan Metode Springate Pada Perusahaan Foods and Beverages yang Terdaftar di Bursa Efek Indonesia Periode 2006-2010. E-Jurnal Repository, 4(1), 5-20.

Almilia, L. S. (2003). Analisis Rasio Keuangan Untuk Memprediksi Kondisi Financial Distress Perusahaan Manufaktur Yang Terdaftar Di Bursa Efek Jakarta. 7(2), 183-210.

Brahmana, R. K. (2007). Identifying Financial Distress Condition in Indonesia Manufacture Industry. 1-19.

Fatmawati, A. (2019). Faktor-Faktor Yang Mempengaruhi Financial Distress Pada Perusahaan Manufaktur Di Indonesia. Jurnal AKSI (Akuntansi Dan Sistem Informasi), 4(1), 19-28.

Fauzy, astuti \& kusumawrdhani (2019). Analisis Faktor-Faktor Yang Mempengaruhi Financial Distress Pada Perusahaan Sektor Property, Real Estate dan Building Construction di Indonessia.

Luh, N., Ayu, M., Lely, N. K., \& Merkusiwati, A. (2015). Pengaruh Rasio Likuiditas, Leverage, Operating Capacity, dan Sales Growth Terhadap Financial Fakultas Ekonomi dan Bisnis Universitas Udayana, Bali, Indonesia perusahaan yang dialami sebelum perusahaan bangkrut ataupun mengalami. 2, 456-469.

Maulidina, D. (2014). Faktor-Faktor Yang Mempengaruhi Financial Distress Pada Perusahaan Manufaktur Yang Terdaftar di BEI Dara Maulidina Universitas Trisakti. 89-106.

Murni, M. (2018). Analisis Faktor-Faktor Yang Mempengaruhi Tingkat Financial Distress Pada Perusahaan Manufaktur Yang Terdaftar Di Bei Tahun 2010-2014. Jurnal Akuntansi dan Bisnis : Jurnal Program Studi Akuntansi, 4(1).

Nabawi, M., \& Efendi, D. (2018). Pengaruh Leverage, Profitabilitas, Aktivitas, Growth Firm Terhadap Kondisi Financial Distress.

Pawitri \& Alteza, 2020. (2020). Analisis pengaruh likuiditas, profitabilitas, 10(2). 
Permana, R. K., Ahmar, N., \& Djadang, S. (2017). Prediksi Financial Distress Pada Perusahaan Manufaktur Di Bursa Efek Indonesia. Esensi: Jurnal Bisnis Dan Manajemen, 7(2), 149-166.

Platt, H. D., \& Platt, M. B. (2002). Predicting Corporate Financial Distress : Reflections on Choice-Based Sample Bias. 26(2), 184-199.

Platt, H. D., \& Platt, M. B. (2008). Financial Distress Comparison Across Three Global Regions. 129-162.

Pusvita Indria Mei Susilowati, M. R. F. (2019). Faktor-Faktor Yang Mempengaruhi Financial Distress Pada Perusahaan Manufaktur di Indonesia. Jurnal AKSI (Akuntansi Dan Sistem Informasi), 4(1), 0-5.

Sari, I. P., Susbiyani, A., \& Syahfrudin, A. (2019). Analisis Faktor-Faktor yang Mempengaruhi Kondisi Financial Distress pada Perusahaan yang Terdapat di BEI Tahun 2016-2018 (Studi Empiris pada Perusahaan Manufaktur Sub Sektor yang Terdaftar di Bursa Efek Indonesia). Jurnal Ilmiah AKuntansi Dan Humanika, 9(2), 191-203. 